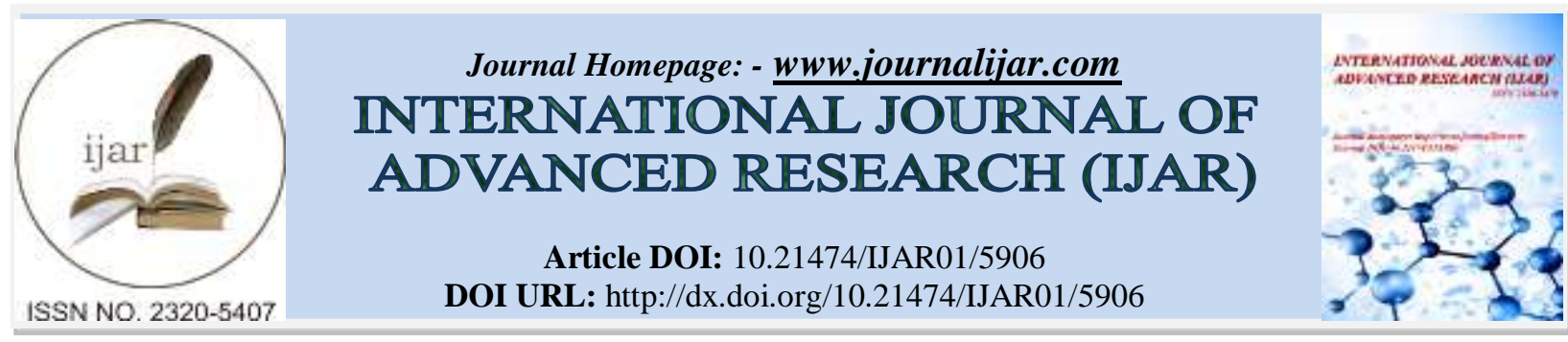

RESEARCH ARTICLE

\title{
AC-ELECTRICAL CONDUCTIVITY AND DIELECTRIC PROPERTIES BEHAVIOUR OF MWCNT/ABS NANOCOMPOSITE.
}

\author{
Abba Alhaji Bala ${ }^{1}$, Abdussalam Balarabe Suleiman ${ }^{1}$, Mukhtar Lawan Adam ${ }^{2}$ and Ibrahim Saadu ${ }^{1}$. \\ 1. Department of Physics, Federal University Dutse, P.M.B.7156 Jigawa State Nigeria. \\ 2. Department of Physics, Bayero University Kano, P.M.B. 3011 Kano State Nigeria.
}

\section{Manuscript Info}

\section{Manuscript History}

Received: 18 September 2017

Final Accepted: 20 October 2017

Published: November 2017

\section{Key words:-}

Dielectric Properties, Multi-Walled

Carbon Nanotubes, Frequency,

Conductivity.

\section{Abstract}

AC-Electrical conductivity and dielectric properties of MultiWalled Carbon Nanotube- Acrylonitrile Butadiene Styrene composite (MWCNT/ABS) has been investigated with MWCNT additive of different concentration percentage. The study showed that electrical conductivity $\sigma$, obeys power law with the frequency exponential factor $\mathrm{S}$ less than one and indicate dielectric loss, $\varepsilon^{\prime \prime}$ not equal to constant. At lower concentration of Carbon Nanotubes, the dielectric constant $\varepsilon^{\prime}$ and dielectric loss $\varepsilon$ " remain constant with increase in frequency but at high concentration, $\varepsilon^{\prime}$ and $\varepsilon^{\prime \prime}$ decrease with an increase in frequency of which indicated that high concentration Carbon Nanotubes play a vital role in increasing dielectric constant and dielectric loss.

Copy Right, IJAR, 2017,. All rights reserved.

\section{Introduction:-}

Carbon elements are essential for living bodies coupled with their technological application in the field of electronics especially organic molecular electronics and bio-electronics.

Since the discovery of carbon isomers for electronics devices application, a number of research works have been carried out with a remarkable and satisfactory result. Carbon nanotubes are new class of carbon isomers which are categorized into single wall nanotube, multi wall nanotube and their ropes or bundles (El-Nahass et al. 2016; Kaneto et al. 1999).

MultiWalled Carbon Nanotubes (MWCNTs) have probe excellently due to their thermal, electrical and mechanical properties. MWCNTs are influential additive to enhance polymer and also an additive to reinforced electrical conductivity in polymer insulation such as polycarbonate (PC), polypropylene (PP), polyethylene (PE) and polymethyl methacrylate (PMMA). The aspect ratio of carbon nanotube when used as conduction nanofiller provides a room for the formation of electric conduction array in the insulating polymer domain at low concentration of nanofiller (Hussien 2011; Lu et al. 2007; Samkana et al. 2013; Abd El-Rahman et al. 2016; El-Nahass et al. 2016).

Dielectric materials become a great subject to study electrical behavior of materials which their application is found to be in industrial devices like microwave filters, dynamic access memory telecommunication and voltage controlled oscillators (Kabir et al. 2001; Izgorodina et al. 2009; . Kuang and Nelson 1998; Gittings et al. 2009; Wen and Chung 2001; Badr et al, 2011; El-Khaled et al. 2016; Cuervo et al. 2014; Es-Souni et al. 2003). Dielectric constant and 
dielectric loss or dissipation factor are very crucial quantities in microelectronics equipment devices designing. These quantities with respect to frequency are the most sensitive and desirable to study polymer structures (Yadav et al. 2010; Cvejić et al. 2008; Dinulović and Rašuo 2009; Botta et al. 2007; Liu et al. 2008). Active electro-polymer nanocomposites are of great choices for several applications because of their remarkable mechanical and electrical properties, high dielectric constant and high electrical conductivity.

This polymer material possesses vital characteristics which include electric conductance and polarization that brought to useful effects on dielectric properties. The two kinds of systems for dielectric polarization are charge carriers and dipole systems in which a range of relaxation process together with their metal-insulator, electrodeelectrolyte, semiconductor-insulator and similar kind systems interfacial phases (Ramani et al. 2015).

$\mathrm{AC}$ conductivity, $\sigma_{\mathrm{ac}}$, give information concerning internal structure of materials at relatively low conducting region, it also differentiate between free band conduction where $\sigma_{\mathrm{ac}}$ decreases with increasing frequency and localized conduction in which $\sigma_{\mathrm{ac}}$ increases with increase in frequency (Abd EL-Rahman et al. 2016). AC conductivity measurements have been widely in application to investigate the ionic motion nature in ionically conducting substances because it is assumed that it is responsible for this kind of conduction. It is also well known that, the electrical behavior of ionically complex conducting materials with respect to frequency generate two domains of behavior namely; nearly constant loss (NCL) in which dielectric loss is almost constant and universal dielectric response (UDR). The ac conductivity dependence on frequency, $\sigma_{\mathrm{ac}}(\omega)$, obeys the power law equation defined as the UDR given in Eqn. 1:

$$
\sigma_{\mathrm{ac}}(\omega)=\mathrm{A} \omega^{\mathrm{S}}
$$

Where: A-Constant and S-Frequency exponent. Whereas, when the value of $S=1$, it implies $\varepsilon=$ Constant, independent of frequency (El-Mallah 2012).

The dielectric relaxation gives fact about conduction mechanism, microstructure of nanocomposite materials (ElGhanem et al. 2013), translational adjustment and orientation of the moving charges present in the dielectric medium. The transferred energy into the dielectric material is as a result of the electric field applied which depends on the dielectric material physical properties. More so, the variation of dielectric figures is attributed to dielectric polarization parameters like ionic, orientation and electronic polarization (Abd EL-Rahman et al. 2016).

\section{EXPERIMENT DETAILS:-}

\section{Materials: -}

ABS; Acrylonitrile-Butadiene-Styrene, (Cycolac Ex-39, Specific gravity 1.03, and MFI 1g/10min) was obtained from SABIC Innovation Plastics. NC7000 was Carbon Nanotubes used in this study which is provided by Nanocyl S.A., Belgium. From the manufacturers, the carbon nanotube is multiwall-made using chemical vapor deposition method (CVD) with an average diameter of $9.5 \mathrm{~nm}$ and length of $1.5 \mathrm{~mm}$.

\section{Composite Preparation:-}

Before mixing of the nanocomposites, the filler and the polymers were dried up under vacuum for 12 hours at $130^{\circ} \mathrm{C}$ and $80^{\circ} \mathrm{C}$ respectively, after then the nanocomposite preparation of MWCNT/ABS was carried out by mix-melting in a batch mixer from Thermo Scientific, Germany, by which the nanocomposite was filled with $0 \mathrm{wt} \%, 0.75 \mathrm{wt} \%$, $1 \mathrm{wt} \%$ and $2 \mathrm{wt} \%$ MWCNT.

The compounding was taking at $50 \mathrm{rpm}, 210^{\circ} \mathrm{C}$ for $12 \mathrm{~mm} ; 9$ min for polymer mix with filler melting and 3 min for pure polymer melting. During melt compounding, an increase in viscosity is observed with nanofiller loading as also showed by El-Ghanem et al. 2013. The plates were compressed for ac measurement using Carver compression mold obtained from Carver Inc. USA, to have plates of thickness $1.1 \mathrm{~mm}$ which were then annealed at $220^{\circ} \mathrm{C}, 25 \mathrm{MPa}$ pressure for $10 \mathrm{~min}$ in the molder.

\section{Results Analysis:- \\ AC Properties Measurement: \\ Impedance: -}

An impedance is a complex number that consists of two parts; real part $\left(Z^{\prime}\right)$ and the imaginary part $\left(Z^{\prime \prime}\right)$ as in equation 2.

$$
\mathrm{Z}=\mathrm{Z}^{\prime}+\mathrm{j} \mathrm{Z}^{\prime \prime}
$$

Where the real part is the resistance, the imaginary part is the loss factor or the reactance and $\quad j=\sqrt{ }-1$ 
Figure 1 indicated a characteristic behavior of an insulator for which $Z^{\prime}$ decrease with an increase in frequency for the nanocomposite with filler concentration below the threshold frequency and unfilled ABS. The figure also shows a transition of $Z^{\prime}$ on frequency, whereas nanocomposite transition behavior is observe to be from frequency independent (Resistive) to frequency dependent (Capacitive) and the cut-off frequency increases with concentration of MWCNT as also indicated in another study (Al-Saleh et al. 2013).

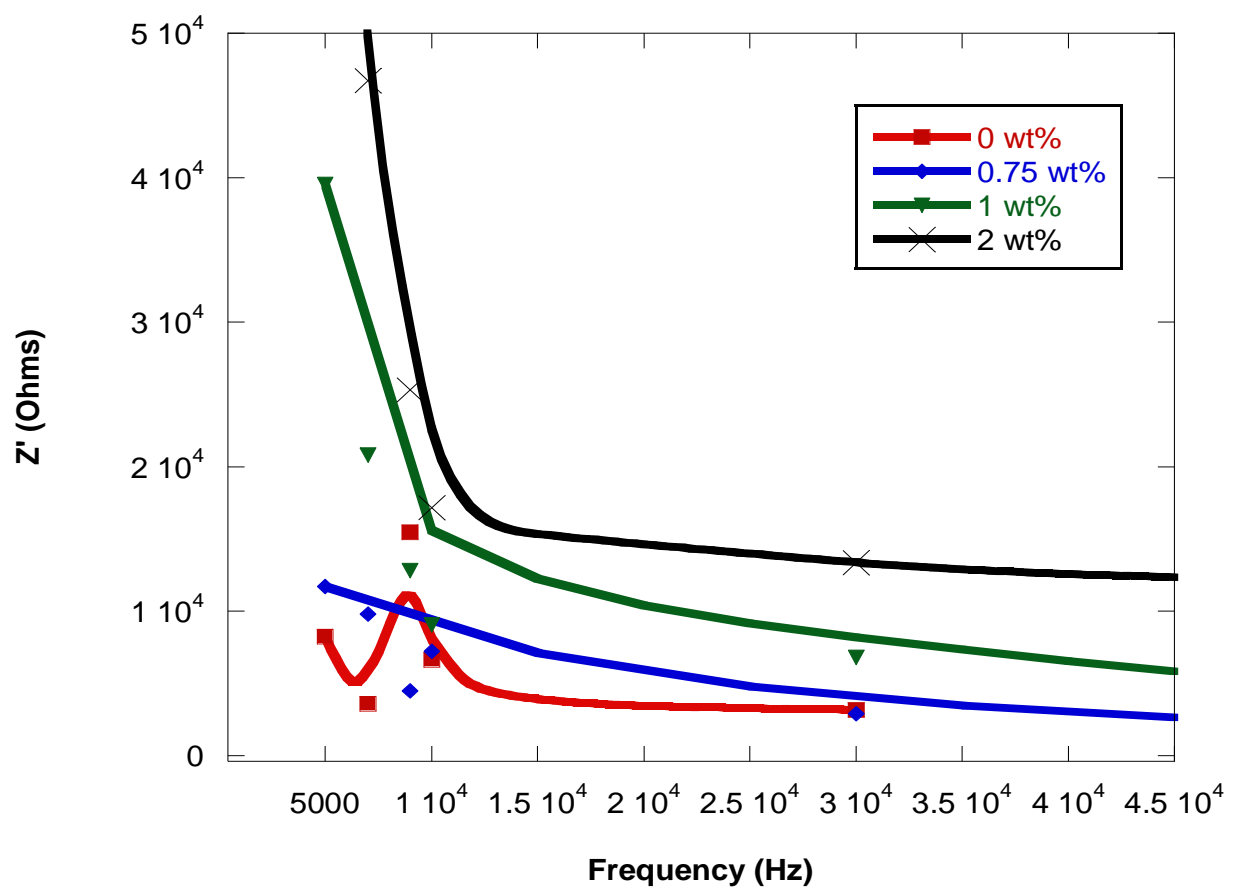

FIG. 1:- Real part (Z') as a function of MWCNT concentration and Frequency

The imaginary impedance magnitude (Z") was presented in figure 2, in which the value increases with an increase in frequency where at the end, it merges at the high frequency region. This indicates that at lower frequency region, there is an effect due to the presence of space charge polarization. This finding came similar to the literature somewhere (Chintaparty and Reddy 2016). 


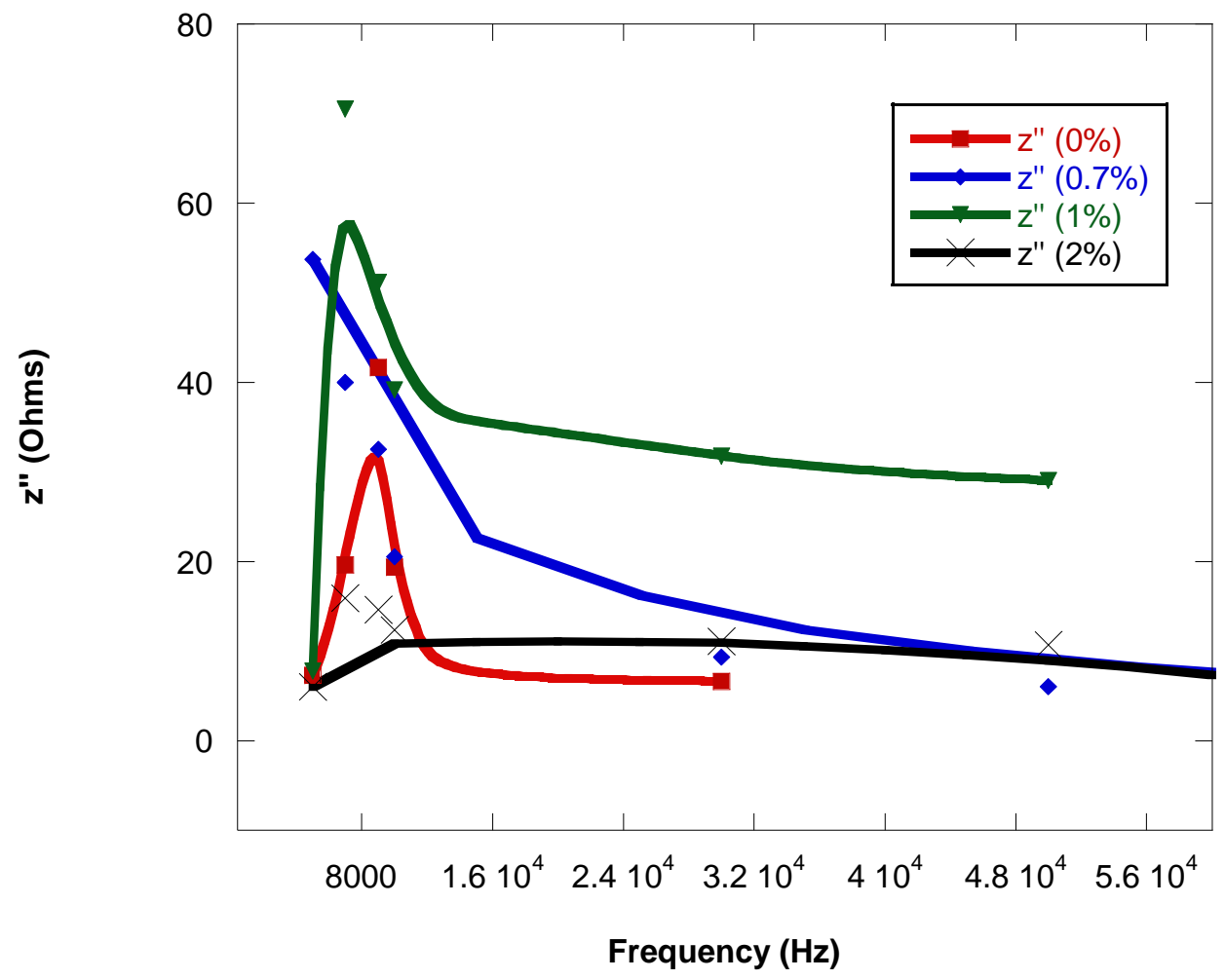

FIG. 2:- Imaginary part (Z") as a function of MWCNT concentration and Frequency

\section{Frequency Dependence: -}

Figures 3 and 4 present the response of frequency to dielectric constant, $\varepsilon^{\prime}$, and dielectric loss, $\varepsilon^{\prime \prime}$, respectively. In the figures, the dielectric constant values and loss factor remain constant with increase in frequency at lower concentration of CNT but shows increase in frequency with decrease of $\varepsilon^{\prime}$ and $\varepsilon^{\prime \prime}$ at high concentration CNT. This indicates that dipole arrange themselves along field direction at low frequency to enhance total polarization (Orientation, Atomic and Electronic), similar results were obtained by El-Mallah 2012; Vivek et al. 2010 for dielectric constant. Moreover, as the frequency increases, the field changes at high speed which make it difficult for the molecular dipole to align thereby reduce their contribution to the polarization. This finding came similar to the literature elsewhere (Ganaie et al. 2014). 


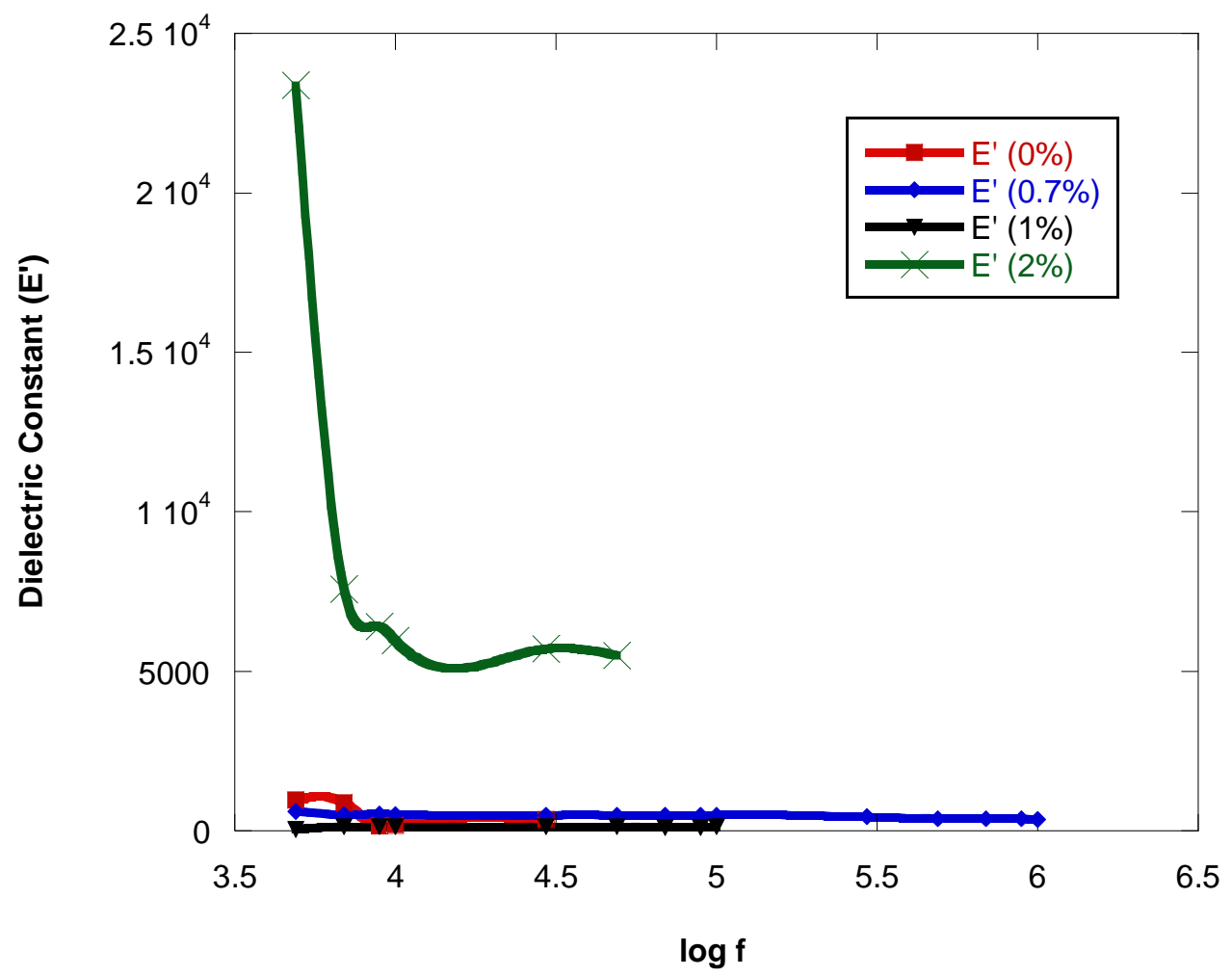

FIG. 3:- A graph of frequency dependence of dielectric constant for the MWCNT concentration 


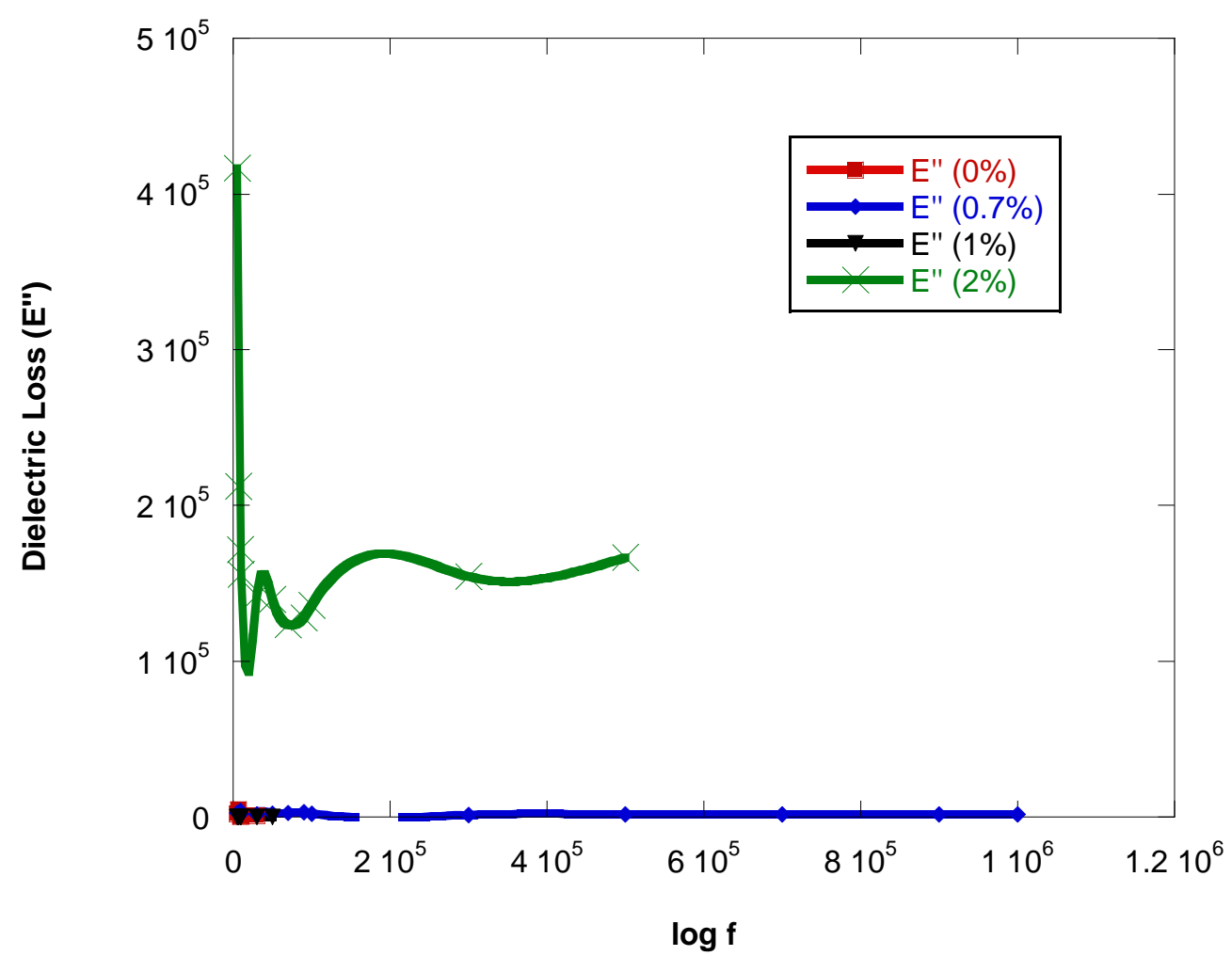

FIG. 4:- A graph of frequency dependence of dielectric loss for the MWCNT concentration

The peaks present in figure 4 of dielectric loss appear as a result of the rotational relaxation of the CNT molecules in the composite and because nanotube is a lighter material, it reorients at high frequency, this observation was abreast with Javed et al. 2006.

The dielectric curve vs. frequency (Fig. 3) shows no peaks as the curve is smoothing slippery compared to figure 3, this is due to the fact that, there are two losses type of dielectric. The first is due to the flow of the real charge into the dielectric called conduction loss and the second is due to the rotation of molecules/atoms in the alternating current field called dielectric loss. As a result of this, the MWCNT/ABS composite conduction is dominance at low frequency by resistance, as such, much conduction loss is produced. The production of this loss give rise to the sample temperature in the ac field and causes a disorder in the motion of the charge carriers that breaks the regular arrangement slowly at the composite interface as shown in figure 3 (Mei-Juan et al. 2009). 


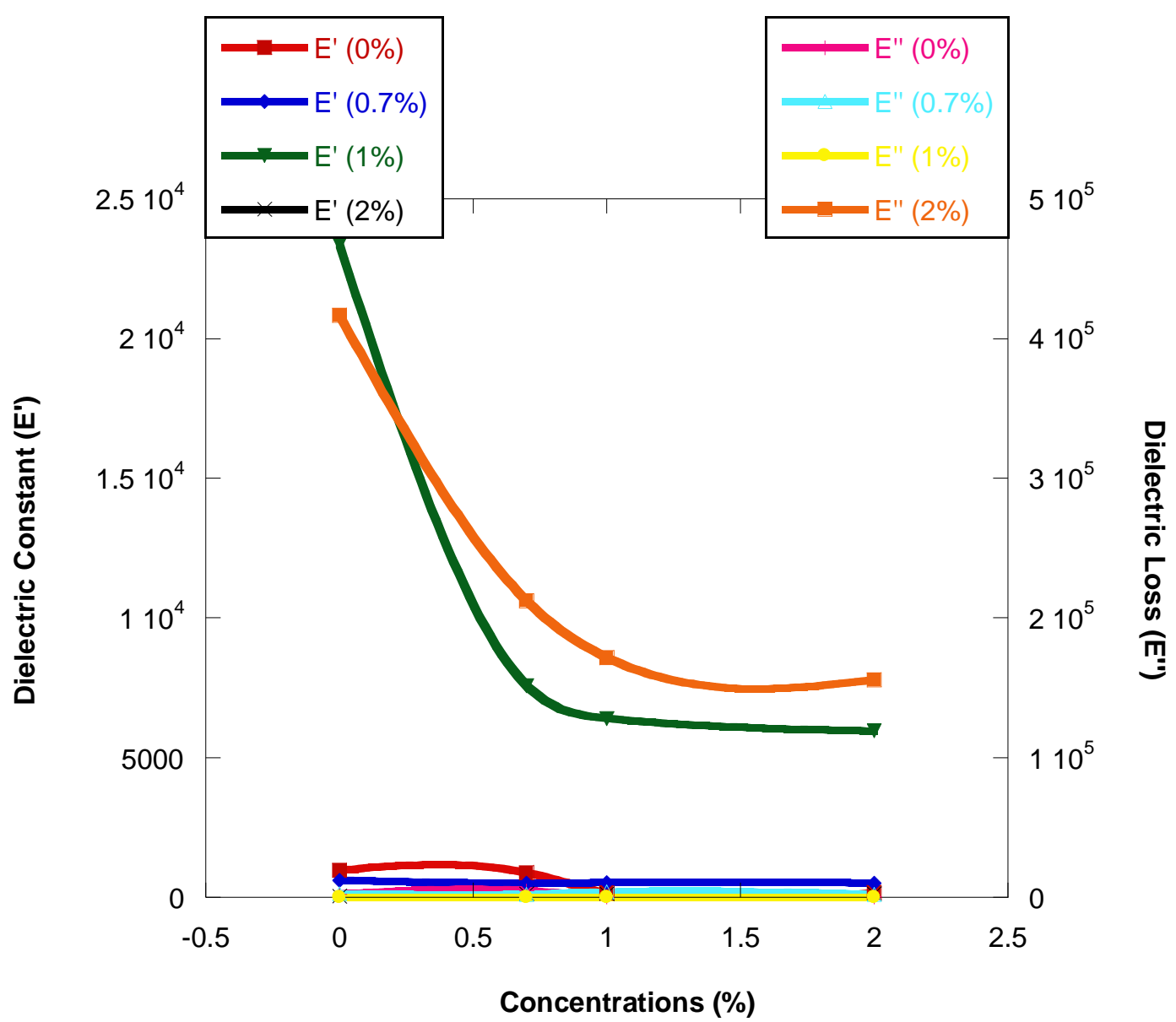

FIG. 5:- Dielectric constant, $\varepsilon$ ', and dielectric loss, $\varepsilon$ ", versus concentration of MWCNT

Dependent composition of dielectric constant, $\varepsilon^{\prime}$, and dielectric loss, $\varepsilon^{\prime \prime}$ with respect to MWCNT concentration is presented in figure 5. It is shown in the figure that $\varepsilon^{\prime}$ and $\varepsilon^{\prime \prime}$ both increase with MWCNT concentration. This clearly indicates that, high concentration CNT play a vital role in increasing $\varepsilon^{\prime}$ and $\varepsilon^{\prime \prime}$ due to defect states increase, the same result was obtain by Ganaie et al. 2014 using Glassy Alloys.

\section{AC Electrical Conductivity: -}

The ac electrical conductivity dependence on frequency for MWCNT/ABS composite is shown in figure 6. It is evident from the figure that the conductivity increases with frequency increase. This is due to the ac electrical conductivity characteristics of CNT which solemnly depend on CNT content in the composite. The conductivity increase with increasing CNT content, whereas, the highest conductivity was found with $1 \%$ concentration which may be due to partial substitution of CNT, similar was also found by Rahman et al. 2014 using Gadolinium substitute Cobalt ferrite. 


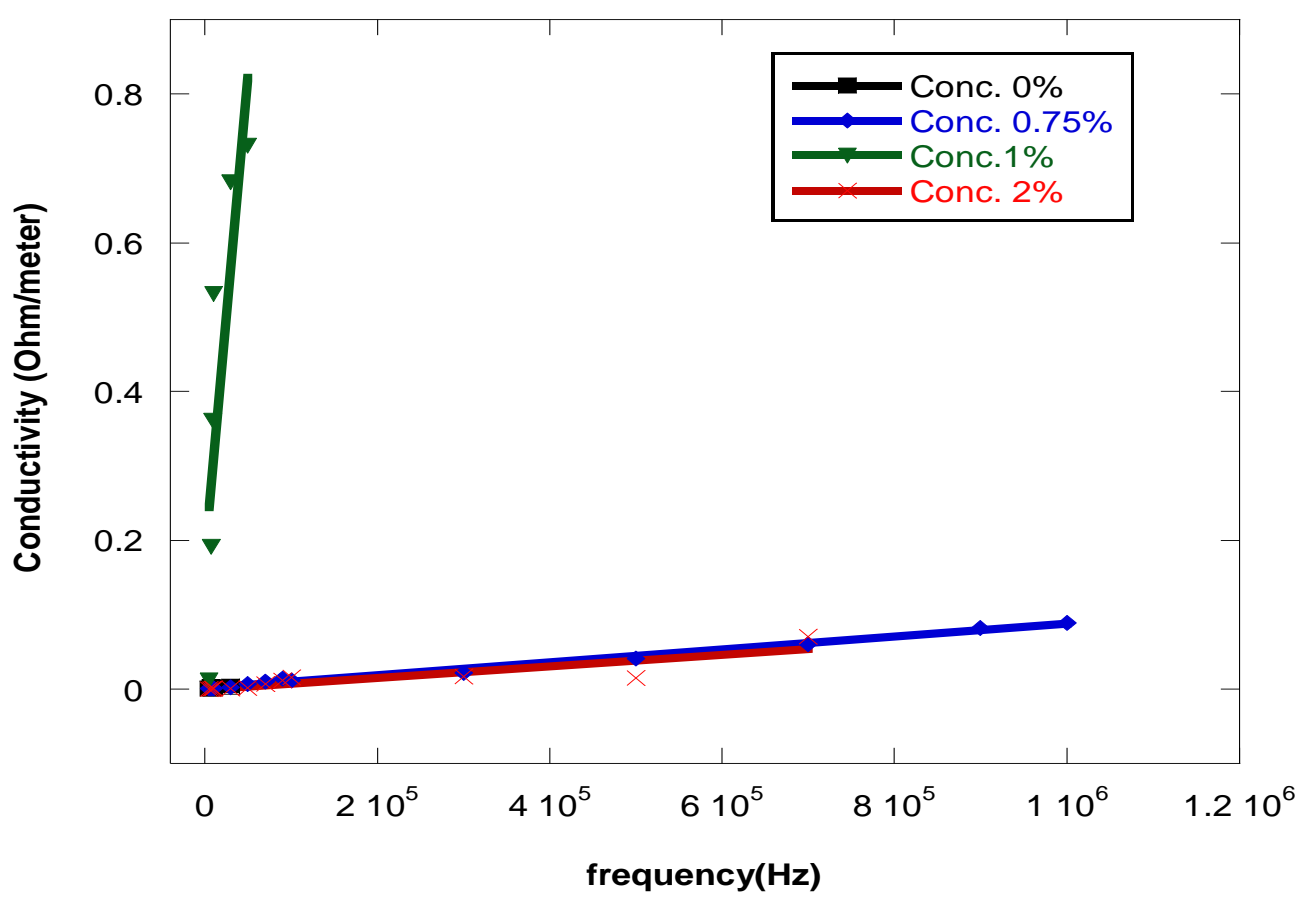

FIG. 6:- The frequency dependence of ac conductivity for MWCNT/ABS samples

The conductivity is frequency dependent for $0 \%, 0.75 \%$ and $2 \%$ and the corresponding circuits of the MWCNT/ABS composites comprise of parallel RC circuit, because a capacitor is equivalent to the open circuit at low frequency circuit state. Since no charge goes through the insulating dielectric surface then, the conductivity is entirely dependent on resistance, as such the conductivity of MWCNT/ABS composite does not have effect with frequency. However, as in the case of $1 \%$ concentration, the conductivity is independent on frequency as it respond to the complete polarization of CNTs due to resistive conduction through the bulk composite. Similar result was also recorded by Mei-Juan et al. 2009.

\section{Conclusion:-}

AC-Electrical conductivity and dielectric properties of MultiWalled Carbon Nanotube- Acrylonitrile Butadiene Styrene composite (MWCNT/ABS) has been investigated. The conductivity increases with increasing CNT content and frequency increase due to the ac electrical conductivity characteristics of CNT which solemnly depend on CNT content in the composite. The study also showed that electrical conductivity $\sigma$, obeys the power law $\sigma_{\mathrm{ac}}=\mathrm{A} \omega^{\mathrm{S}}$ with the frequency exponential factor $\mathrm{S}<1$ that indicate $\varepsilon$ " not equal to constant and depends on frequency. The dielectric constant $\varepsilon^{\prime}$ and dielectric loss $\varepsilon^{\prime \prime}$ remain constant with increase in frequency at lower concentration of CNT but shows increase in frequency with decrease of $\varepsilon^{\prime}$ and $\varepsilon^{\prime \prime}$ at high concentration which indicated that high concentration CNT play a vital role in increasing dielectric constant and dielectric loss

\section{Acknowledgement:-}

The authors are grateful to Prof. Hasan M. El-Ghanem, Physics Department, Jordan University of Science and Technology, Jordan, for using material laboratory.

\section{Reference:-}

1. Abd EL-Rahman, K. F., Darwish, A. A. A., Saleem, I. Q. and Hanafy, T. A. (2016): AC Conductivity and Dielectric Relaxation Behavior of $\mathrm{Sb}_{2} \mathrm{~S}_{3}$ Bulk Material. Journal of Elec. Materi., 0361: 5235 
2. Al-Saleh, M. H., Haya, K. A., Yazan, A. H., Hasan, M. E. and Saadi, A. (2013): Impedance characteristics and conductivity of CNT/ABS nanocomposites. J. Phys. D. 46: 385305 (8pp)

3. Badr, A. M., Elshaikh, H. A., Ashraf, I. M. (2011): Impacts of Temperature and Frequency on the Dielectric Properties for Insight into the Nature of the Charge Transports in the $\mathrm{Tl}_{2} \mathrm{~S}$ Layered Single Crystals. Journal of Modern Phy., 2: 12-25

4. Botta, P. M., Mira, J., Fondado, A. and Rivas, J. (2007): Increase of the dielectric constant near a magnetic phase transition in $\mathrm{La}_{0.5} \mathrm{Ca}_{0.5} \mathrm{MnO}_{3}$. Materials Letters, 61: 2990-2992

5. Cuervo, A., Dans, P. D., Carrascosa, J. L., Orozco, M., Gomila, G. and Fumagalli, L. (2014): Direct measurement of the dielectric polarization properties of DNA. PNAS, Aug. 18

6. Cvejić, Ž., Rakić, S., Jankov, S., Skuban, S., Kapor, A. (2008): Dielectric Properties of Nanosized $\mathrm{ZnFe}_{2} \mathrm{O}_{4}$. Proces. and Appli. of Ceram. 2(1): 53-56

7. Dinulović, M. and Rašuo, B. (2009): Dielectric Properties Modeling of Composite Materials. FME Transactions 37: 117-122

8. El-Khaled, D., Castellano, N. N., Gázquez, J. A., Perea-Moreno, A. and Manzano-Agugliaro, F. (2016): Dielectric Spectroscopy in Biomaterials: Agrophysics. Materials, 9, 310

9. El-Mallah, H. M. (2012): AC Electrical Conductivity and Dielectric Properties of Perovskite $(\mathrm{Pb}, \mathrm{Ca}) \mathrm{TiO}_{3} \mathrm{Ceramic}$. Acta Physica Polonica A, 122(1)

10. EL-Nahass, M. M., EL-Zaidia, E. F. M., Darwish, A. A. A. and Salem, G. F., (2016): Journal of Elec. Mat. 03

11. Es-Souni, M., Zhang, N., Iakovlev, S., Solterbeck, C. H. and Piorra, A. (2003): Thickness and erbium doping effects on the electrical properties of lead zirconate titanate thin films. Thin Solid Films, 440: 26-34

12. Gittings, J. P., Bowen, C. R., Dent, A. C. E., Turner, I. G., Baxter, F. R. and Chaudhuri, J. B. (2009): Electrical characterization of hydroxyapatite-based bioceramics. Acta Biomaterialia, 5: 743-754

13. Hasan, M. E., Saa'di, A., Mohammed, H. A., Yazan, A. H. and Wael, S. (2013): Effect of DC-bias on the dielectric behavior of CNT/ABS nanocomposites. Physica B. 418: 41-46

14. Hussien, B. (2011): The D.C and A.C Electrical Properties of (PMMA - $\mathrm{Al}_{2} \mathrm{O}_{3}$ ) Composites. Euro. Jour. of Scient. Res. 52(2): 236-242

15. Izgorodina, E. I., Forsyth, M. and MacFarlane, D. R. (2009): On the components of the dielectric constants of ionic liquids: ionic polarization? Phys. Chem. 11: 2452-2458

16. Javed, A., Muhammad A., Muhammad, I. S. (2006): Dielectric Properties of Cholesterol Derivatives. Rom. Journ. Phys., $51(7-8): 819-826$

17. K. F. ABD EL-Rahman, A. A. A. Darwish, S. I. Qashou and T.A. Hanafy, Journal of Elec. Mat. (2016)

18. Kabir, M. F., Daud, W. M., Khalid, K. B. and Sidek, H. A. A. (2001): Temperature Dependence of the Dielectric Properties of Rubber Wood. Woo. and Fib. Sci. 33(2): 233-238

19. Kaneto, K., Tsuruta, M., Sakai, G., Cho, W. Y. and Ando, Y. (1999): Electrical conductivities of multi-wall carbon nano tubes. Synthetic Metals, 103: 2543-2546

20. Kuang, W. and Nelson, S. O. (1998): Low-Frequency Dielectric Properties of Biological Tissues: A Review with some new Insights. ASAE 41(1): 173-184

21. Liu, G., Wang, C., Wang, C., Qiu, J., He, M., Xing, J., Jin, K., Lu, H. and Yang, G. (2008): Effects of interfacial polarization on the dielectric properties of BiFeO3 thin film capacitors. App. Phy. Lett. 92: 122903

22. Lu, W., Wang, D. and Chen, L. (2007): Near-Static Dielectric Polarization of Individual Carbon Nanotubes. Nano. Lett., 7(9): 2729-2733

23. Mei-Juan, J., Zhi-Min, D., Michael, B., Fabien, M. and Jinbo, B. (2009): Broad-frequency dielectric behaviors in multiwalled carbon nanotube/ rubber nanocomposites. Journ. of Appl. Phy., 106: 084902

24. Mohsin, G., Shabir, A. and Shama, I. M. Z. (2014): Electrical Conductivity and Dielectric Properties of $\mathrm{Se}_{100-\mathrm{x}} \mathrm{Te}_{\mathrm{x}}$ Alloy. Intern. Journ. of Phy. and Astron., 2(2)

25. Rahman, M. T., Vargas, M. and Ramana, C. V. (2014): Structural characteristics, electrical conduction and dielectric properties of gadolinium substituted cobalt ferrite. Journ. of Alloys and Comp. 617: 547-562

26. Rajababu, C., Ramamanohar, N. R. (2016): Effect of precursor on optical, dielectric properties of zirconia crystalline powder prepared by hydrothermal method. Adv. Mater. Lett. 7(3): 235-238

27. Ramani, R., Ramachandran, R., Amarendra, G. and Alam, S. (2015): Direct correlation between free volume and dielectric constant in a fluorine-containing polyimide blend. Journal of Phy. Conference Series, 618: 012025

28. Vivek, Y., Anil, K., Sudeep, S. and Sinha, A. K. (2010): Analyses of dielectric properties of fertilizers (urea and diammonium phosphate) in aqueous solution at different temperatures in microwave frequency. Int. J. Phys. Sci. 5(16): 2466-2470

29. Wen, S., Chung, D. D. L. (2001): Effect of admixtures on the dielectric constant of cement paste. Cement and Concrete Res. 31: 673-677

30. Yadav, V. S., Devendra, K. Sahu., Yashpal, S. and Dhubkarya, D. C. (2010): The Effect of Frequency and Temperature on Dielectric Properties of Pure Poly Vinylidene Fluoride (PVDF) Thin Films. IMECS: 3978-988. 